\title{
Changes in impaired self-awareness after acquired brain injury in patients following intensive neuropsychological rehabilitation
}

Citation for published version (APA):

Smeets, S. M. J., Vink, M., Ponds, R. W. H. M., Winkens, I., \& van Heugten, C. M. (2017). Changes in impaired self-awareness after acquired brain injury in patients following intensive neuropsychological rehabilitation. Neuropsychological Rehabilitation, 27(1), 116-132.

https://doi.org/10.1080/09602011.2015.1077144

Document status and date:

Published: 01/01/2017

DOI:

10.1080/09602011.2015.1077144

Document Version:

Publisher's PDF, also known as Version of record

Document license:

Taverne

Please check the document version of this publication:

- A submitted manuscript is the version of the article upon submission and before peer-review. There can be important differences between the submitted version and the official published version of record.

People interested in the research are advised to contact the author for the final version of the publication, or visit the DOI to the publisher's website.

- The final author version and the galley proof are versions of the publication after peer review.

- The final published version features the final layout of the paper including the volume, issue and page numbers.

Link to publication

\footnotetext{
General rights rights.

- You may freely distribute the URL identifying the publication in the public portal. please follow below link for the End User Agreement:

www.umlib.nl/taverne-license

Take down policy

If you believe that this document breaches copyright please contact us at:

repository@maastrichtuniversity.nl

providing details and we will investigate your claim.
}

Copyright and moral rights for the publications made accessible in the public portal are retained by the authors and/or other copyright owners and it is a condition of accessing publications that users recognise and abide by the legal requirements associated with these

- Users may download and print one copy of any publication from the public portal for the purpose of private study or research.

- You may not further distribute the material or use it for any profit-making activity or commercial gain

If the publication is distributed under the terms of Article $25 \mathrm{fa}$ of the Dutch Copyright Act, indicated by the "Taverne" license above, 


\title{
Changes in impaired self-awareness after acquired brain injury in patients following intensive neuropsychological rehabilitation
}

\author{
Sanne M. J. Smeets' ${ }^{1}$, Martie Vink ${ }^{2}$, \\ Rudolf W. H. M. Ponds ${ }^{1,3}$, Ieke Winkens ${ }^{1}$, and \\ Caroline M. van Heugten ${ }^{1,4}$
}

\author{
${ }^{1}$ School for Mental Health and Neuroscience (MHeNS), Department of \\ Psychiatry and Neuropsychology, Maastricht University, Maastricht, The \\ Netherlands \\ ${ }^{2}$ Amsterdam Rehabilitation Research Center, Amsterdam, The Netherlands \\ ${ }^{3}$ Department of Psychiatry and Psychology, Maastricht University Medical \\ Center (MUMC), Maastricht and Adelante, Rehabilitation Center, \\ Hoensbroek, The Netherlands \\ ${ }^{4}$ Faculty of Psychology and Neuroscience, Department of Neuropsychology \\ and Psychopharmacology, Maastricht University, Maastricht, The \\ Netherlands
}

(Received 30 January 2015; accepted 24 July 2015)

The objective of this study was to investigate changes in self-awareness impairments in outpatients with acquired brain injury (ABI) and the effects these changes have on rehabilitation. Participants were 78 patients with ABI (8.3 years post-injury) who followed an intensive outpatient neuropsychological rehabilitation programme. This longitudinal study comprised pre (T1) and post (T2) measurements and a one-year follow-up (T3). Thirty-eight patients completed the study. The main outcome domains were self-awareness, depressive symptoms, psychological and physical dysfunction, and health-related quality of life (HRQoL). Patients were divided into three awareness groups: underestimation, accurate estimation, and overestimation of competencies. Most patients who underestimated their competencies at the start of treatment

Correspondence should be addressed to Caroline van Heugten, School for Mental Health and Neuroscience, Maastricht University, location DRT 12, P.O. Box 616, 6200 MD, Maastricht, The Netherlands. E-mail: c.vanheugten@maastrichtuniversity.nl

No potential conflict of interest was reported by the authors. 
accurately estimated their competencies directly after treatment (9 out of 11 patients). These patients also exhibited the largest treatment effects regarding depressive symptoms, psychological and physical dysfunction, and HRQoL. Most patients with impaired self-awareness (i.e., overestimation of competencies) at the start of treatment continued to overestimate their competencies after treatment (10 out of 14 patients). These patients exhibited a significant decrease in depressive symptoms but no other treatment effects. The results indicate that changes in outcome are related to changes in awareness, which underline the importance of taking into account different awareness groups with respect to treatment effects.

Keywords: Self-awareness; Awareness; Brain injury; Rehabilitation; Treatment outcome.

\section{INTRODUCTION}

Patients with acquired brain injury (ABI) often have an impaired awareness of the deficits that result from the injury. They have difficulty in the appraisal of their strengths and weaknesses and the implications of the changes that result from the ABI for life in the present and future (Fleming, Strong, \& Ashton, 1996; Prigatano \& Schacter, 1991). Impaired self-awareness typically refers to the overestimation of competencies. However, there is also a group of patients who underestimate their competencies. This distinction is clinically and scientifically important because these groups have different characteristics. In a recent study, we demonstrated that patients with ABI who underestimated their competencies reported more depressive symptoms compared with patients who accurately estimated or overestimated their competencies. Patients who overestimated their competencies reported the same level of depressive symptoms as patients who accurately estimated their competencies (Smeets et al., 2014).

A better awareness of deficits at the start of rehabilitation is associated with more favourable outcomes with respect to independence in complex everyday tasks, psychological or emotional adjustment, and employment outcomes (Leung \& Liu, 2011; Ownsworth \& Clare, 2006). Furthermore, changes in awareness appear to influence changes in outcome. One study (Ownsworth, Desbois, Grant, Fleming, \& Strong, 2006) with outpatient individuals with ABI who were, on average, four years post-injury, investigated whether changes in awareness influenced changes in employment status. It was demonstrated that patients who became more aware of their deficits also showed an improvement in their employment status (Ownsworth et al., 2006). To our knowledge, this is the only study to address the effects of changes in awareness on other outcomes. 
These findings suggest that it is relevant to improve the awareness of deficits in patients who have suffered an ABI. In a recent paper, Schrijnemaekers, Smeets, Ponds, van Heugten, and Rasquin (2013) reviewed nine interventions that aimed to improve the awareness of deficits in patients with ABI. Although the evidence for effective interventions was scarce, the authors propose some tentative guidelines for a general approach to improve awareness. In patients who have some intellectual awareness, i.e., who have the ability to understand that a specific function is impaired (Crosson et al., 1989), an intervention should include a combination of training in functional skills in multiple settings and multimodal feedback related to performance (Schrijnemaekers et al., 2013).

The Intensive NeuroRehabilitation (INR) programme is a holistic treatment programme provided in The Netherlands for patients in the chronic phase after ABI. The INR programme includes the training of multiple functional skills and offers multimodal feedback. The programme focuses on increasing individuals' awareness of their deficits and on the acquisition of compensatory strategies, adequate coping skills, acceptance of the consequences of the injury, and efficient interpersonal skills (van Balen, Jorritsma, Groet, \& Vink, 2002). The patients following the INR programme are a relevant group to study in order to increase our understanding of awareness deficits after ABI.

Therefore, the primary objective of this study was to investigate changes in self-awareness in patients with ABI who followed the INR programme. We hypothesised that both patients who overestimated and underestimated their competencies at the start of INR would have accurate awareness after INR. The secondary objective of this study was to investigate the effects of changes in self-awareness on outcome domains relevant to the INR programme, i.e., depressive symptoms, psychological and physical dysfunction, and health-related quality of life (HRQoL). We hypothesised that patients whose awareness had improved after INR would benefit more from INR with respect to depressive symptoms, psychological and physical dysfunction, and HRQoL compared with patients who did not exhibit improved awareness.

\section{METHODS}

\section{Participants}

The participants were patients with ABI who were enrolled in the INR programme of the rehabilitation centre Reade (Amsterdam, The Netherlands) between August 2008 and December 2013. In addition, a significant other (SO) of each patient participated in the study. 
Rehabilitation professionals, outpatient support services, and physicians refer patients to the INR programme. The inclusion criteria for admission are as follows: (1) ABI of a non-progressive nature (e.g., traumatic brain injury or stroke) documented by medical/surgical records and/or brain imaging; (2) time since injury at least 12 months; (3) age between 18 and 65 years; and (4) demonstration of at least some knowledge regarding the consequences of the injury based on clinical judgement. The exclusion criteria are as follows: (1) language deficits that interfere with communication; (2) behavioural or psychiatric disorders that could interfere with group functioning (e.g., aggression or extreme disinhibition); (3) insufficient command of the Dutch language; or (4) substance abuse. An extra exclusion criterion for this study was that only the data of patients with complete awareness assessments at the pre-treatment measurement (T1) were used.

\section{Intervention}

The INR programme is described in detail elsewhere (van Balen et al., 2002). It is based on the holistic, therapeutic milieu approach described by Ben-Yishay (2000). Briefly, INR is an outpatient group programme with eight patients per group. The staff consists of neuropsychologists, physical therapists, a vocational therapist, a physiatrist, and a secretary. Each patient is assigned to a personal coach with whom they have a weekly counselling session. The programme length is 14 weeks, which consists of seven weeks of training followed by a two-week break and another seven weeks of training. The patients attend the programme four days per week with 3-4.5 hours of group training per day and one individual session per week.

To increase awareness of their deficits, the patients receive psycho-education and feedback from various sources. During psycho-education (one hour group session per training day), the patients learn about the brain and its functions in general and, more specifically, about the potential dysfunctions after brain injury. Written information, experiential exercises and role-plays help patients to become (more) aware of the characteristics of their brain injury. In addition, feedback is provided in various forms throughout the INR programme to promote awareness. Each training day, the patients are trained in setting realistic goals to promote the use of compensatory strategies to manage the consequences of the injury; they receive interpersonal training and have group discussions. The patients receive feedback from the staff, group members or guests that participate in the programme for one day. The patients also perform exercises that are videotaped, and receive feedback on their performance from the staff and fellow group members while watching the video (van Balen et al., 2002). 


\section{Study design and procedure}

The current study is part of an on-going longitudinal cohort study. T1 is the pre-treatment measurement assessed in the four weeks before the start of the INR programme. Maximally four weeks after the end of the programme, posttreatment measurements were taken (T2), and one year after the end of the programme, there was a follow-up measurement (T3). The questionnaires used in this study were completed at these three time-points at the rehabilitation centre $(\mathrm{T} 1, \mathrm{~T} 2)$ or at home (T3). The questionnaires completed at home were returned by mail.

The neuropsychological assessment and questionnaires were standard clinical procedures within the INR programme. The patients provided informed consent for the anonymous use of their data for scientific purposes. A review procedure by a medical ethics committee was not needed for the use of anonymous and routinely collected data.

\section{Measurements}

\section{Demographic and injury-related information}

The following information was extracted from the patients' files: date of birth, gender, educational level, and type and date of brain injury. Information regarding the gender and relation of SOs to the patient were collected. The educational level of the patients was rated on a six-point scale according to a standardised Dutch classification system (Verhage, 1964). These categories were reduced to two categories: low education (classifications 1-4) and high education (classifications 5-8).

\section{Self-awareness}

The Patient Competency Rating Scale (PCRS; Prigatano et al., 1986) is a 30-item questionnaire used to assess impaired self-awareness after brain injury. Respondents are asked to rate how well a patient can perform certain activities at this moment. The items are rated on a 5-point Likert scale from 1 (cannot do) to 5 (can do with ease). The patient rates his own behaviour, and an SO rates the patient's behaviour. The discrepancy between the patient's score and the SO's score is a measure of the self-awareness of competencies. The discrepancy score is calculated by subtracting the SO's score from the patient's score. A greater discrepancy indicates greater impairment in the patient's self-awareness (range -120 to 120). Positive discrepancies indicate overestimation and negative discrepancies indicate underestimation of difficulties. In addition to the discrepancy scores, a categorical awareness score was calculated that divides the patients into three awareness groups: underestimation, accurate estimation and overestimation of 
competencies (Prigatano \& Altman, 1990; Smeets et al., 2014). The patients were classified into groups by calculating the number of items in which the patient $(\mathrm{P})$ rating was lower than the SO rating $(P<\mathrm{SO})$, exactly equal to the $\mathrm{SO}$ rating $(P=\mathrm{SO})$, and greater than the $\mathrm{SO}$ rating $(P>\mathrm{O})$. The patients were classified in the underestimation group when the number of $P<\mathrm{SO}$ items was greater than the numbers of $P=\mathrm{SO}$ and $P>\mathrm{SO}$ items. To be classified in the accurate estimation group, the number of $P=\mathrm{SO}$ items had to be the highest. Finally, to be classified in the overestimation group, the number of $P>$ SO items had to be the highest. The PCRS has good psychometric properties (Smeets, Ponds, Verhey, \& van Heugten, 2012).

\section{Depressive symptoms}

The Beck Depression Inventory-II (BDI-II; Beck, Steer, \& Brown, 1996; van der Does, 2002) is a 21-item self-report questionnaire used to measure symptoms of depression. Items are rated on a 4-point scale. The scores on these items are summed, and the total score ranges from 0 to 63. Scores from 0-13 indicate minimal depression; 14-19 mild depression; 20-28 moderate depression; and 29-63 indicate severe depression. The BDI-II has been proven to have good psychometric qualities in a variety of samples (Wang \& Gorenstein, 2013), including patients with traumatic brain injury (Green, Felmingham, Baguley, Slewa-Younan, \& Simpson, 2001).

\section{General psychological and physical dysfunction}

The Symptom Checklist-90 - Revised (SCL-90-R; Arrindell \& Ettema, 2005; Derogatis, 1977) is a 90-item self-report questionnaire used to assess general psychological and physical dysfunction in recent time. Respondents indicate on each item to what degree they have suffered from a specific complaint in the previous week. Items are rated on a 5-point scale from 0 (not at all) to 4 (extremely) and summed, which results in a total score that can range from 0 to 360 . Higher scores indicate that patients experienced more psychological and physical dysfunction in the previous week. The SCL-90-R has been used in a variety of patient groups, including outpatient neurological patients (Ruis et al., 2014).

\section{Health-related quality of life}

The Quality of Life in Brain Injury (QOLIBRI; von Steinbuechel, Petersen, \& Bullinger, 2005) is a self-report questionnaire that assesses HRQoL after traumatic brain injury. The QOLIBRI consists of 37 items and covers six HRQoL dimensions (Cognition; Self; Daily life and autonomy; Social relationships; Emotions; and Physical problems). Items are scored on a 1-5 scale and the scores are converted to a $0-100$ scale. Higher scores represent 
a better quality of life. The test-retest reliability and internal consistency are good (von Steinbüchel et al., 2010).

\section{Statistical analyses}

\section{Sample characteristics}

Descriptive analyses were performed to describe the patient characteristics, baseline levels of deficit awareness (PCRS), depressive symptoms (BDI-II), general psychological and physical dysfunction (SCL-90-R), and HRQoL (QOLIBRI). Consistent with the manual, the QOLIBRI data were discarded if more than one-third of the items was missing (The Qolibri Task Force), and the SCL-90-R data were discarded if more than 10 items were missing (Arrindell \& Ettema, 2005). For the PCRS and BDI-II, the data were discarded when more than $25 \%$ of the items were missing. If for any scale the amount of missing items was within the allowed range, the total score of the scale was imputed by extrapolating the total score of the items available ((total score/\#completed items)*total \#items on scale).

With respect to patient characteristics, an investigation determined whether or not there were significant differences between the awareness groups on the baseline scores of the outcome measures (BDI-II, SCL-90-R, and QOLIBRI) at T1. This investigation was performed using multiple regression analyses with the awareness groups (overestimation, accurate estimation, and underestimation) as the independent variables, and the outcome measures scores at $\mathrm{T} 1$ as the dependent variables. The awareness groups were dummy coded with the accurate awareness group as the reference group. For each outcome measure, a separate analysis was performed. Age, gender, and education were entered as the covariates.

\section{Primary objective: Changes in awareness}

Changes in awareness were operationalised as transfers from one awareness group to another group between T1 and T2 $(3 \times 3$ table $)$. This approach resulted in nine potential transfer groups (e.g., patients who underestimated at $\mathrm{T} 1$ and $\mathrm{T} 2$; patients who underestimated at $\mathrm{T} 1$ who became accurate estimators at $\mathrm{T} 2$; patients who underestimated at $\mathrm{T} 1$ and overestimated at $\mathrm{T} 2$ ). Changes in awareness are described and visualised. To investigate the changes in awareness, we would have preferred to use a statistical method that could test within-group changes. Within-group changes are typically tested with methods that calculate the difference score between two time points (e.g., $t$-tests). However, because awareness was operationalised as a discrepancy score (i.e., difference score), the results from these statistical methods would not be interpretable because we would be interpreting the difference of a difference. 


\section{Secondary objective: Influence of changes in awareness on outcome}

Within each transfer group, the changes in outcome measures were examined to investigate the influence of the changes in deficit awareness on depressive symptoms (BDI-II), psychological and physical dysfunction (SCL-90-R), and HRQoL (QOLIBRI) between T1 and T2, as well as T2 and T3. The data for these previously described change groups were only interpreted when groups consisted of five or more patients. Because not all outcome measure scores were normally distributed in all groups at both time points, Wilcoxon Signed Rank tests were performed to statistically explore the changes in the outcome measures. From the standardised test statistic, the effect size $r$ was calculated. The following interpretation of the magnitude of the effect was used: small effect $r=.1$; medium effect $r=.3$; large effect $r=.5$ (Cohen, 1992).

Results were considered significant if $p<.05$. For each analysis, the assumptions for the test concerned were checked. All statistical analyses were conducted using SPSS 20.0 for Mac OS X.

\section{RESULTS}

\section{Patient characteristics and between-group differences at T1}

Seventy-eight patients were included in the study. The demographic and injury-related characteristics are presented in Table 1. Fourteen patients $(17.9 \%)$ underestimated their competencies, 44 patients $(56.4 \%)$ accurately estimated their competencies and 20 patients $(25.6 \%)$ overestimated their competencies. On the BDI-II, $13(17.8 \%)$ of 73 patients for whom data were available reported no or minimal depressive symptoms, 23 patients (31.5\%) reported mild symptoms, 23 patients $(31.5 \%)$ reported moderate symptoms and 14 patients (19.2\%) reported severe depressive symptoms.

On the SCL-90-R, the patients in this sample reported a significantly increased level of psychological and physical dysfunction $(M=179.4, S D$ $=50.9$ ) compared with a Dutch norm sample of healthy individuals, $M=$ 118.3, $S D=32.4, t(2444)=7.6, p<.001$ (Arrindell \& Ettema, 2005). On the QOLIBRI, the studied sample had a lower score $(M=55.3, S D=10.7)$ than a sample of individuals with TBI $(M=64.6, S D=18.2$; Truelle et al., 2010); however, this difference was not significant, $t(871)=-1.6, p>.05$.

The patients who underestimated their competencies on T1 had a significantly increased BDI-II score compared with the patients who accurately estimated their competencies $(B=6.3, S E B=2.7$, Beta $=.29,95 \%$ CI $0.95-$ 11.7, $\left.p<.05, N=73, R^{2}=.09\right)$. With regard to the SCL-90-R and the QOLIBRI, no significant differences between groups were identified. 
TABLE 1

Sample characteristics at T1

\begin{tabular}{|c|c|c|c|c|c|}
\hline & & $\begin{array}{l}\text { Underestimation } \\
\qquad(\mathrm{N}=14)\end{array}$ & $\begin{array}{l}\text { Accurate } \\
\text { estimation } \\
(\mathrm{N}=44)\end{array}$ & $\begin{array}{l}\text { Overestimation } \\
\quad(\mathrm{N}=20)\end{array}$ & $\begin{array}{c}\text { All } \\
(\mathrm{N}=78)\end{array}$ \\
\hline \multicolumn{6}{|c|}{ Frequency $(\%)$} \\
\hline Male & & $9(64.3)$ & $21(47.7)$ & $15(75)$ & $45(57.7)$ \\
\hline \multirow{2}{*}{$\begin{array}{l}\text { Educational } \\
\text { level }\end{array}$} & Low & $8(57.1)$ & $26(59.1)$ & $11(55)$ & 45 (57.7) \\
\hline & High & $6(42.9)$ & $18(40.9)$ & $9(45)$ & $33(42.3)$ \\
\hline \multirow{6}{*}{$\begin{array}{l}\text { Type of brain } \\
\text { injury }\end{array}$} & TBI & $4(28.6)$ & $24(54.5)$ & $7(35)$ & 35 (44.9) \\
\hline & Vascular & $3(21.4)$ & $8(18.2)$ & $6(30)$ & $17(21.8)$ \\
\hline & Tumour & $1(7.1)$ & $5(11.4)$ & $4(20)$ & $10(12.8)$ \\
\hline & Anoxia & $3(21.4)$ & $1(2.3)$ & $1(5)$ & $5(6.4)$ \\
\hline & Other $^{\mathrm{a}}$ & $3(21.4)$ & $6(13.6)$ & $2(10)$ & $11(14.1)$ \\
\hline & & Mean $(S D)$ & & & \\
\hline \multicolumn{2}{|l|}{ Age in years } & $43.5(11.5)$ & $40.5(12.3)$ & $45.2(13.3)$ & $42.2(12.5)$ \\
\hline \multicolumn{2}{|c|}{ Years post-injury } & $6.2(6.8)$ & $7.6(8.6)$ & $7.4(4.9)$ & $7.3(7.4)$ \\
\hline \multicolumn{2}{|c|}{ PCRS discrepancy score } & $-14.2(5.7)$ & $-0.73(6.8)$ & $18.3(7.2)$ & $1.7(12.8)$ \\
\hline \multicolumn{2}{|l|}{ BDI-II } & $26.1(10)$ & $\begin{array}{l}20.2(8.1) \\
(n=40)\end{array}$ & $\begin{array}{l}19.7(8) \\
(n=19)\end{array}$ & $\begin{array}{l}21.2(8.7) \\
(n=73)\end{array}$ \\
\hline \multicolumn{2}{|l|}{ SCL90 } & $203.7(52)$ & $182.5(50.8)$ & $155.7(42)$ & $179.4(50.9)$ \\
\hline \multicolumn{2}{|l|}{ QOLIBRI } & $50.5(8.6)$ & $55.2(11.0)$ & $58.9(10.5)$ & $55.3(10.7)$ \\
\hline
\end{tabular}

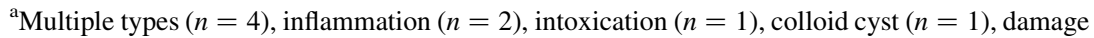
caused by radiation for non-Hodgkin lymphoma $(n=1)$; epilepsy - status epilepticus $(n=1)$ and surgery $(n=1)$.

For 38 of the 78 patients complete awareness assessments were available at all three time points. Since not all patients completed the study it was explored if there were any differences in the characteristics reported in Table 1 between patients who had complete awareness assessments at all three time-points $(n=38)$ and patients who had complete awareness assessments at T1 or at T1 and T2 $(n=40)$. Only on the QOLIBRI was a difference found. The group with complete assessments at all three time-points had a significant higher score at $\mathrm{T} 1$ than the group of patients who did not complete the study. There were no differences between the groups on the other characteristics. Furthermore, at T1 five patients had incomplete BDI-II data, at T2 one patient had incomplete QOLIBRI data, and at T3 one patient had incomplete BDI-II data. Therefore these patients were excluded from analyses that included the questionnaire for which data were incomplete.

\section{Primary objective: Changes in awareness}

At T2, 64 patient awareness assessments were available. The transfers in groups between $\mathrm{T} 1$ and $\mathrm{T} 2$ are shown in Table 2. In four groups, there 
TABLE 2

Changes in awareness: Transfer from one awareness group to another between $\mathrm{T} 1$ and $\mathrm{T} 2$

\begin{tabular}{cccccc}
\hline & \multicolumn{3}{c}{$T 2$} & \\
\cline { 3 - 5 } & & Underestimation & Accurate & Overestimation & Total \\
& $\mathrm{N}(\%)$ & $\mathrm{N}(\%)$ & $\mathrm{N}(\%)$ & $\mathrm{N}$ \\
\hline $\mathrm{T} 1 \quad$ & $1(9)$ & $9(82)$ & $1(9)$ & 11 \\
& Underestimation & $4(10)$ & $25(64)$ & $10(26)$ & 39 \\
& Accurate & $1(7)$ & $3(21)$ & $10(71)$ & 14 \\
& Overestimation & 6 & 37 & 21 & 64 \\
\hline
\end{tabular}

were more than five observations. These groups are described further. Of the 11 patients who underestimated their competencies at T1, nine accurately estimated their competencies at T2 (Group 1,82\% of the underestimation group at T1). Of the 39 patients who accurately estimated their competencies at $\mathrm{T} 1,25$ remained in this group at $\mathrm{T} 2$ (Group 2, 64\% of the accurate estimation group at T1). Ten of these 39 patients overestimated their competencies at T2 (Group 3, 26\% of the accurate estimators at T1). Of the 14 patients who overestimated their competencies at $\mathrm{T} 1,10$ also overestimated at $\mathrm{T} 2$ (Group 4, 71\% of the overestimation group at T1).

In Figure 1, changes in the discrepancy PCRS scores are visualised. The graph shows that the patients who overestimate their competencies and have

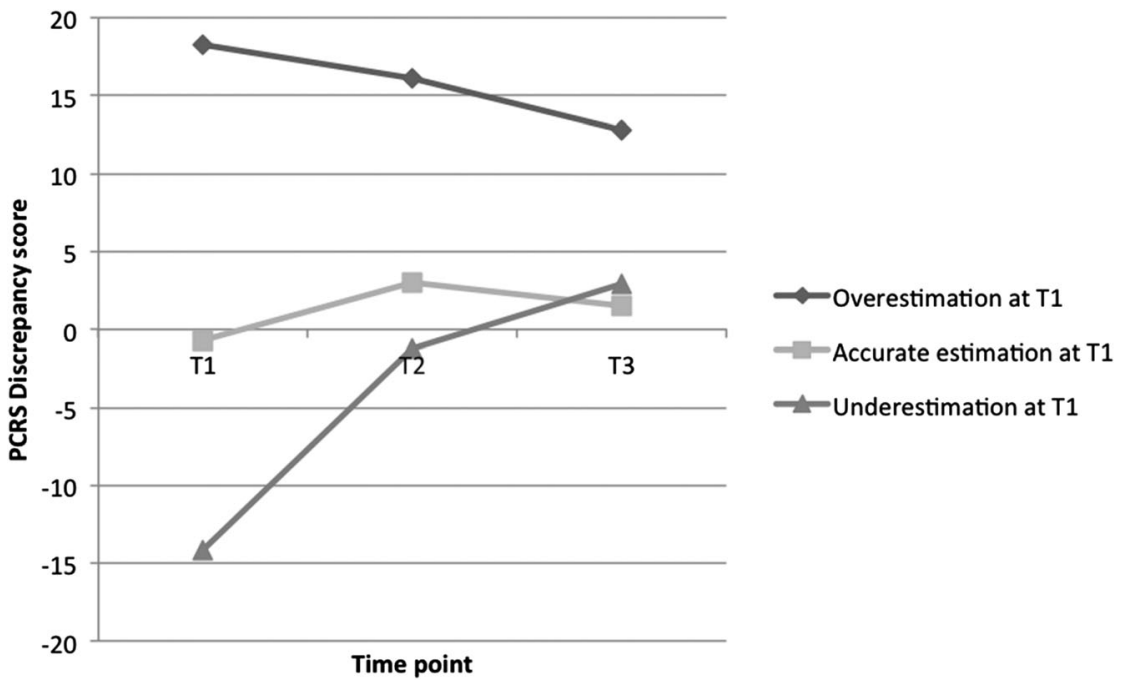

Figure 1. Pre-treatment (T1), post-treatment (T2) and one year follow-up (T3) PCRS discrepancy scores per awareness group. Groups are based on T1 data. Group ( $n \mathrm{~T} 1 / n \mathrm{~T} 2 / n \mathrm{~T} 3)$ : Overestimation (20/14/10); Accurate estimation (44/39/21); Underestimation (14/11/7). 
increased discrepancy scores at $\mathrm{T} 1$ continue to have increased discrepancy scores at T2 and T3 compared with the patients who accurately estimated their competencies at T1. Post-hoc analyses (multiple regression analysis with group as the predictor and age, gender, and education as the covariates) demonstrated that this difference in the discrepancy score between the patients who overestimate and the patients who accurately estimate their competencies at T1, T2 and T3, was significant. The discrepancy score at T1 of the underestimation group was significantly lower than the discrepancy score of the accurate estimation group; however, the discrepancy score was no longer significantly different at $\mathrm{T} 2$ and $\mathrm{T} 3$ between these two groups (data not shown).

\section{Secondary objective: Influence of changes in awareness on outcome}

The results regarding the changes in awareness and the BDI-II, SCL-90-R, and QOLIBRI between $\mathrm{T} 1$ and $\mathrm{T} 2$ are shown in Table 3. The results for Group 1 (the patients who underestimate their competencies at T1 but accurately estimate their competencies after INR), Group 2 (accurate estimators at T1 who remain accurate estimators at T2), and Group 3 (accurate estimators at $\mathrm{T} 1$ who overestimate at $\mathrm{T} 2$ ) demonstrated that the depressive symptoms (BDI-II) and psychological and physical dysfunction (SCL-90-R) significantly decreased in these groups, whereas the HRQoL (QOLIBRI)

TABLE 3

Influence of changes in awareness on BDI-II, SCL-90-R and QOLIBRI

\begin{tabular}{|c|c|c|c|c|c|c|}
\hline & \multirow[b]{2}{*}{ Group } & \multirow[b]{2}{*}{$\mathrm{N}$} & \multicolumn{2}{|c|}{ Median $(I Q R ;$ range $)$} & \multirow{2}{*}{$\begin{array}{c}\text { Test } \\
\text { statistic } Z\end{array}$} & \multirow{2}{*}{$\begin{array}{l}\text { Effect } \\
\text { size } r\end{array}$} \\
\hline & & & $T 1$ & $T 2$ & & \\
\hline \multirow[t]{4}{*}{ BDI-II } & 1 & 9 & $20(13 ; 11-52)$ & $11(8 ; 0-18)$ & $-2.7^{* *}$ & -.64 \\
\hline & 2 & 22 & $16.5(9.5 ; 7-43)$ & $13.5(13.5 ; 0-31.5)$ & $-3.2^{* *}$ & -.48 \\
\hline & 3 & 9 & $18(12 ; 14-32)$ & $9(15 ; 0-21)$ & $-2.4^{*}$ & -.57 \\
\hline & 4 & 9 & $15(7 ; 8-30)$ & $11(5-30)$ & $-2.5^{*}$ & -.60 \\
\hline \multirow[t]{4}{*}{ SCL-90-R } & 1 & 9 & $166(108 ; 116-272)$ & $138(46 ; 107-208)$ & $-2.5^{*}$ & -.60 \\
\hline & 2 & 25 & $151(72 ; 101-304)$ & $132(32 ; 98-253)$ & $-3.7^{* * *}$ & -.52 \\
\hline & 3 & 10 & $176(85.5 ; 140-255)$ & $133.5(46 ; 101-178)$ & $-2.7^{* *}$ & -.60 \\
\hline & 4 & 10 & $136(51 ; 111-198)$ & $130.5(26 ; 103-182)$ & -1.1 & -.24 \\
\hline \multirow[t]{4}{*}{ QOLIBRI } & 1 & 9 & $59.6(16.7 ; 41.3-68.4)$ & $71.9(7.7 ; 62.1-90.3)$ & $2.7^{* *}$ & .64 \\
\hline & 2 & 25 & $66.3(20.4 ; 40.2-81.6)$ & $71.2(17.4 ; 42.1-83.9)$ & $2.6^{* *}$ & .37 \\
\hline & 3 & 10 & $54.4(16.5 ; 41.1-73.8)$ & $76.6(13 ; 54.2-82.4)$ & $2.7^{* *}$ & .60 \\
\hline & 4 & 9 & $67.9(12.6 ; 48.4-90.9)$ & $72.5(12.2 ; 55.2-89.4)$ & 1.2 & .29 \\
\hline
\end{tabular}

Group (1) underestimation T1 —accurate estimation T2; (2) accurate estimation T1—accurate estimation $\mathrm{T} 2$; (3) accurate estimation $\mathrm{T} 1$-overestimation $\mathrm{T} 2$; (4) overestimation $\mathrm{T} 1$-overestimation $\mathrm{T} 2$.

${ }^{*} p<.05 ;{ }^{* *} p<.01 ;{ }^{* * *} p<.001$. 
significantly increased. The strengths of the effects were the largest in Group $1\left(r_{\text {Group } 1}=.6\right.$ to .64$)$, followed by Group $3\left(r_{\text {Group } 3}=.57\right.$ to .60$)$, and Group 2 ( $r_{\text {Group } 2}=.37$ to .52 ). Group 4 (the patients who overestimate their competencies at $\mathrm{T} 1$ and $\mathrm{T} 2$ ) exhibited a significant decrease in depressive symptoms after INR, but no significant changes in psychological and physical dysfunction or HRQoL.

Between T2 and T3, Groups 1 and 2 showed no significant changes in outcome. Group $3(N=6)$ exhibited a significant increase in depressive symptoms $($ Median $=21 ; \mathrm{IQR}=10 ; Z=2.2 ; p<.05 ; r=.63$ ) and in psychological and physical dysfunction (Median $=168.5 ; \mathrm{IQR}=63$; $Z=2.2 ; p<.05 ; r=.63$ ) and a significant decrease in HRQoL (Median $=61.5 ; \mathrm{IQR}=26 ; Z=-2.0 ; p<.05 ; r=-.57$ ) between $\mathrm{T} 2$ and $\mathrm{T} 3$. For Group 4, the differences in the scores on the BDI-II and QOLIBRI between T2 and T3 were not tested $(n<5)$.

\section{DISCUSSION}

The primary objective of this study was to investigate changes in self-awareness in outpatients with ABI who followed an intensive holistic treatment programme. It was hypothesised that both patients who underestimated or overestimated their competencies at the start of the programme would exhibit more accurate estimations, i.e., would have better awareness of their deficits, after treatment and one year later. However, this hypothesis was rejected, since the INR programme appeared to be helpful for patients who underestimated their competencies at the start of treatment, but not for patients who overestimated. Most patients who overestimated at the start of treatment continued to overestimate their competencies directly after treatment. Only three of 14 patients in the overestimation group adopted a more accurate view of their competencies post-treatment, and one patient changed to the underestimation group.

The secondary goal of this study was to explore the effect of changes in awareness on outcome measures. We hypothesised that patients who exhibited improved awareness after treatment would benefit more from INR with respect to depressive symptoms, psychological and physical dysfunction, and HRQoL, than the patients who did not improve with respect to awareness (i.e., the patients who continued to under- or overestimate competencies). With respect to depressive symptoms, all investigated groups (i.e., underestimation pre-treatment to accurate estimation post-treatment; accurate estimation pre- and post-treatment; accurate estimation pre-treatment and overestimation post-treatment; overestimation pre- and post-treatment) reported significantly fewer symptoms post-treatment compared with pretreatment. The largest clinical effect was identified in the patients who 
underestimated their competencies pre-treatment and accurately estimated them post-treatment, which is in line with our hypothesis. On average, these patients changed from moderate to mild depressive symptoms. The other groups, on average, changed from mild to minimal depression.

With regard to psychological and physical dysfunction and HRQoL, the patients who underestimated their competencies at T1 and accurately estimated their competencies at $\mathrm{T} 2$, and the patients who were in the accurate estimation group at both time-points improved on these variables. These improvements may have been influenced by a decrease in depressive symptoms because depressive symptoms significantly decreased in both groups. However, we were unable to test this hypothesis because of the small number of patients in the transfer groups. The patients who continued to overestimate did not significantly improve regarding the psychological and physical dysfunction and HRQoL measures. This finding suggests that persistence in overestimation or impaired self-awareness hinders positive treatment outcomes. It must be noted that on the SCL-90-R, the group of patients who continued to overestimate their competencies had better scores on these measures at T1 compared with the patients in the other groups; thus, less improvement was possible.

A remarkable group of patients is those who accurately estimate their competencies before treatment but overestimate them directly after. This finding was unexpected, and further analysis of these 10 patients indicated that this change was also maladaptive. One year after the INR programme, this group of patients reported significantly more depressive symptoms and psychological and physical dysfunction and lower HRQoL compared with directly after treatment. Thus, the treatment effect weakened for this group, whereas the other groups did not exhibit a significant increase or decrease in the outcome measures between T2 and T3. This effect could be because of overoptimistic ideas at the end of treatment and unrealistic expectations of the treatment effects. If these expectations are not met, patients may be disappointed, which may result in an increase in depressive feelings and a decrease in HRQoL.

Although better awareness at the start of rehabilitation has been related to more favourable rehabilitation outcomes (for an overview see Ownsworth \& Clare, 2006), in our study, however, outcome is not necessarily worse for patients who have impaired self-awareness (i.e., overestimation). First, they experienced fewer problems before the treatment compared with the other groups. Second, the exploratory data indicate that for the patients who continue to overestimate their competencies, the observed treatment effect is smaller or absent. Thus, they benefit less from treatment compared with the patients in the other groups. This finding might be because of the persistent nature of impaired self-awareness, which may result from neuronal dysfunction, because most patients who overestimate at the start of INR also 
overestimate at the end. A potential neurological correlate of impaired selfawareness was recently studied by Ham et al. (2014). The authors of this study demonstrated that neural activity in the fronto-parietal control network (FPCN) was abnormal in patients with impaired self-awareness after traumatic brain injury. The FPCN is involved in performance monitoring, and dysfunction of this network might interfere with learning and adaption, which consequently hinders rehabilitation and other treatment efforts (Ham et al., 2014). This hypothesis fits our finding that patients with impaired self-awareness (i.e., patients who continue to overestimate their competencies) do not benefit from treatment as much as the other transfer groups. In our data, information on neural activity in the FPCN is not available, but we do recommend investigating this relationship further in future research on awareness after brain injury.

In addition to its focus on increasing the awareness of deficits, the holistic treatment approach is also targeted at reducing the indirect psychological effects (e.g., frustration, anger, depression, shame, anxiety and distress) of the brain injury (van Balen et al., 2002). This might explain why the INR programme is most beneficial to patients who underestimate their competencies at the start of treatment. Based on our clinical impressions, underestimation is most likely a psychological reaction in the chronic phase after brain injury. Patients with ABI are confronted with failure, and over time, they may continue to avoid specific situations because they are anxious about failing again. Patients may even begin to avoid things they can do and underestimate their competencies (see also the fear avoidance model in relation to chronic pain by Vlaeyen \& Linton, 2000). In holistic treatment programmes therapists try to break this vicious circle, and this might explain the improvements identified in this study in the patients who underestimate their competencies at pre-treatment but accurately estimate their competencies post-treatment.

\section{Strengths and limitations}

One of the unique aspects of this research is that it is the first longitudinal group study that investigates changes in awareness deficits and the effects these changes in awareness have on other outcomes from the perspective of three awareness groups: underestimation, overestimation and accurate estimation of competencies. However, the study is not a legitimate effect study because of the absence of a control condition. Thus, we cannot prove that this specific treatment programme induced the changes in awareness. Furthermore, although this study had a fairly large sample size $(N=78)$, because we divided the sample into groups, and lost participants to follow-up, the sample size of the transfer groups was small. Therefore, the statistical power is low, and the results should be considered exploratory. Nevertheless, this study 
provides exploratory evidence for specific changes in awareness and the effects these changes have on outcome.

In addition, by using the ratings of SOs on the PCRS as reference, we assume that SOs have full awareness and rate the patients' behaviour reliably. However, this might not always be the case and could have led to potential bias. Nevertheless, it is not uncommon to use SOs in awareness research using discrepancy methods (see, for instance, McBrinn et al., 2008; Prigatano \& Altman, 1990). Also, the PCRS is only one method to measure awareness, and other sources can be used (for an overview see Smeets et al., 2012). However, the PCRS is one of the recommended instruments based on its psychometric properties which is essential for use in research (Smeets et al., 2012).

\section{Clinical implications}

The results indicate that the intensive holistic neurorehabilitation programme may have been especially helpful for the patients who underestimated their competencies at the start of treatment. In general, this small group of patients became more accurate estimators of their competencies, and this change also positively influenced changes in depressive symptoms, physical and psychological dysfunction, and HRQoL. This group also had the most to gain, especially with respect to depressive symptoms, because they had the worst scores at the start of treatment. We do acknowledge, however, that these conclusions are based on only a small sample size.

Furthermore, patients who overestimated at the start of treatment profited the least from the programme with respect to changes in awareness and other outcome measures. Although improvements in self-awareness is one goal of INR and other holistic neurorehabilitation programmes (Ben-Yishay, 2000), a more intensive and specific intervention technique that is not part of a broader treatment programme may be required to improve true impairments in selfawareness (Schrijnemaekers et al., 2013).

\section{CONCLUSION}

This study demonstrated that even in the chronic phase after injury, awareness regarding competencies could change in patients with $\mathrm{ABI}$, especially for patients who underestimate their competencies at the start of treatment. In general, patients with impaired self-awareness (i.e., overestimation of competencies) at the start of treatment continue to overestimate their competencies after the treatment. The results also demonstrate that changes in awareness during treatment influenced treatment outcome. Again, patients who underestimated before treatment and were accurate estimators after treatment exhibited greater improvements in the investigated outcome measures, whereas 
patients with persistent impaired self-awareness did not exhibit improvements on all outcome measures. However, these are exploratory results, and further research is necessary to confirm these findings. Nevertheless, these findings underline the importance of taking into account different awareness groups with respect to treatment effects.

\section{REFERENCES}

Arrindell, W., \& Ettema, J. H. M. (2005). Symptom checklist. Handleiding bij een multidimensionele psycholpathologie-indicator [Symptom checklist. Manual of a multidimensional psychopathology indicator]. Amsterdam: Harcourt Test Publishers.

van Balen, E., Jorritsma, T., Groet, E., \& Vink, M. (2002). A cognitive rehabilitation approach to long-term consequences following brain injury: Dutch practice. In W. Brouwer, E. van Zomeren, I. Berg, A. Bouma, \& E. de Haan (Eds.), Cognitive rehabilitation. A clinical neuropsychological approach (1st ed., pp. 71-105). Amsterdam: Boom.

Beck, A. T., Steer, R. A., \& Brown, G. (1996). Manual for the Beck Depression Inventory-II. San Antonio, TX: Psychological Corporation.

Ben-Yishay, Y. (2000). Post-acute neuropsychological rehabilitation: A holistic approach. In A. L. Christensen \& B. P. Uzzell (Eds.), International handbook of neuropsychological rehabilitation (pp. 127-136). New York: Kluwer Academic/Plenum Publishers.

Cohen, J. (1992). A power primer. Psychological Bulletin, 112, 155-159. doi:10.1037/ 00332909.112.1.155

Crosson, B., Barco, P. P., Velozo, C. A., Bolesta, M. M., Cooper, P. V., Werts, D., .. . Brobeck, T. C. (1989). Awareness and compensation in postacute head injury rehabilitation. The Journal of Head Trauma Rehabilitation, 4(3), 46-54. doi:http://journals.lww.com/headtraumarehab/ Abstract/1989/09000/Awareness_and_compensation_in_postacute_head.8.aspx

Derogatis, L. R. (1977). SCL-90-R: Administration, scoring and procedures manual. Baltimore: John Hopkins University School of Medicine, Clinical Psychometrics Research Unit.

van der Does, A. J. W. (2002). BDI-II-NL. Handleding. De Nederlandse versie van de Beck Depression Inventory-2nd edition [BDI-II-NL manual. The Dutch version of the Beck Depression Inventory-2nd edition]. Lisse: Harcourt Test Publishers.

Fleming, J., Strong, J., \& Ashton, R. (1996). Self-awareness of deficits in adults with traumatic brain injury: How best to measure? Brain Injury, 10, 1-16. doi:10.1080/026990596124674

Green, A., Felmingham, K., Baguley, I. J., Slewa-Younan, S., \& Simpson, S. (2001). The clinical utility of the Beck Depression Inventory after traumatic brain injury. Brain Injury, 15, 1021-1028. doi:10.1080/02699050110074187

Ham, T. E., Bonnelle, V., Hellyer, P., Jilka, S., Robertson, I. H., Leech, R., \& Sharp, D. J. (2014). The neural basis of impaired self-awareness after traumatic brain injury. Brain, 137, 586-597. doi:10.1093/brain/awt350

Leung, D. P. K., \& Liu, K. P. Y. (2011). Review of self-awareness and its clinical application in stroke rehabilitation. International Journal of Rehabilitation Research, 34, 187-195. doi:10.1097/MRR.0b013e3283487f31

McBrinn, J., Colin Wilson, F., Caldwell, S., Carton, S., Delargy, M., McCann, J., . . McGuire, B. (2008). Emotional distress and awareness following acquired brain injury: An exploratory analysis. Brain Injury, 22, 765-772. doi:10.1080/02699050802372208

Ownsworth, T., \& Clare, L. (2006). The association between awareness deficits and rehabilitation outcome following acquired brain injury. Clinical Psychology Review, 26, 783-795. doi:10.1016/j.cpr.2006.05.003 
Ownsworth, T., Desbois, J., Grant, E., Fleming, J., \& Strong, J. (2006). The associations among self-awareness, emotional well-being, and employment outcome following acquired brain injury: A 12-month longitudinal study. Rehabilitation Psychology, 51, 50-59. doi:10. 1037/0090-5550.51.1.50

Prigatano, G. P., \& Altman, I. M. (1990). Impaired awareness of behavioral limitations after traumatic brain injury. Archives of Physical Medicine and Rehabilitation, 71, 1058-1064.

Prigatano, G. P., Fordyce, D., Zeiner, H., Roueche, J., Pepping, M., ... Wood, B. (1986). Neuropsychological rehabilitation after brain injury. Baltimore, MD: Johns Hopkins University Press.

Prigatano, G. P., \& Schacter, D. L. (1991). Introduction. In G. P. Prigatano \& D. L. Schacter (Eds.), Awareness of deficit after brain injury: Clinical and theoretical issues (pp. 3-16). New York City: Oxford University Press.

Ruis, C., van den Berg, E., van Stralen, H. E., Huenges Wajer, I. M. C., Biessels, G. J., Kappelle, J., ... van Zandvoort, M. J. E. (2014). Symptom checklist 90-revised in neurological outpatients. Journal of Clinical and Experimental Neuropsychology, 36, 170-177. doi:10. 1080/13803395.2013.875519

Schrijnemaekers, A., Smeets, S. M., Ponds, R. W., van Heugten, C. M., \& Rasquin, S. (2013). Treatment of unawareness of deficts in patients with acquired brain injury: A systematic review. The Journal of Head Trauma Rehabilitation, 29(5), E9-E30. doi:10.1097/01. HTR.0000438117.63852.b4

Smeets, S. M., Ponds, R. W. H. M., Wolters Gregório, G., Pouwels, C. J. G., Visscher, A. J., Winkens, I., \& van Heugten, C. M. (2014). Impaired awareness of deficits in individuals with neuropsychiatric symptoms after acquired brain injury: Associations with treatment motivation and depressive symptoms. Neuropsychology, 28, 717-725. doi:10.1037/ neu0000068

Smeets, S. M., Ponds, R. W., Verhey, F. R., \& van Heugten, C. M. (2012). Psychometric properties and feasibility of instruments used to assess awareness of deficits after acquired brain injury: A systematic review. The Journal of Head Trauma Rehabilitation, 27, 433-442. doi:10.1097/HTR.0b013e3182242f98

von Steinbüchel, N., Wilson, L., Gibbons, H., Hawthorne, G., Höfer, S., Schmidt, S. , .. Truelle, J. L. (2010). Quality of life after brain injury (QOLIBRI): Scale development and metric properties. Journal of Neurotrauma, 27, 1167-1185.

von Steinbuechel, N., Petersen, C., Bullinger, M., \& the QOLIBRI Task Force. (2005). Assessment of health-related quality of life in persons after traumatic brain injury-development of the QOLIBRI, a specific measure. Acta Neurochirochirurgica Supplement, 93, 43-49.

The Qolibri Task Force. QOLIBRI Scoring. Retrieved from http://www.qolibrinet.com/scoring. htm

Truelle, J. L., Koskinen, S., Hawthorne, G., Sarajuuri, J., Formisano, R., von Wild, K., ... the Qolibri Task Force. (2010). Quality of life after traumatic brain injury: The clinical use of the QOLIBRI, a novel disease-specific instrument. Brain Injury, 24, 1272-1291.

Verhage, F. (1964). Intelligence and age: Research among the Dutch between 7 and 77 years of age (in Dutch). Assen: Van Gorcum.

Vlaeyen, J. W., \& Linton, S. J. (2000). Fear-avoidance and its consequences in chronic musculoskeletal pain: A state of the art. Pain, 85, 317-332. doi:10.1016/S0304-3959(99)00242-0

Wang, Y. P., \& Gorenstein, C. (2013). Psychometric properties of the Beck Depression Inventory-II: A comprehensive review. Revista Brasileira de Psiquiatria, 35, 416-431. doi:10. 1590/1516-4446-2012-1048 